\title{
Logistics Informatization of Industrial Enterprises Based on Big Data and Its Application in Industrial Supply Chain Management
}

\author{
KeWang* \\ Industrial culture research center, Zibo Vocational College,Zibo,Shandong, China \\ *Corresponding Author.
}

\begin{abstract}
In the current digital information age, logistics is no longer the isolated transportation and storage of enterprises, nor is it the appendage of enterprise production and sales. This paper studies the logistics informatization of industrial enterprises and its application in industrial supply chain management under the background of big data. By analyzing the formation mechanism and covering modules of logistics informatization, this paper constructs the evaluation index system of logistics enterprise informatization. Based on the fuzzy evaluation method and the specific data of logistics information modernization of Chinese enterprises, this paper gives an application example of the evaluation model. Finally, this paper puts forward a reasonable analysis of the information construction of China's logistics enterprises in the future. The results show that this method can improve the efficiency of logistics informatization and supply chain management of industrial enterprises, and has certain reference significance for the research of logistics intelligence of industrial enterprises.
\end{abstract}

Keywords:Big data, industrial enterprises, logistics informatization, industrial supply chain management

\section{Introduction}

Market globalization and global distribution of enterprises, especially the global distribution of enterprise supply chain operation, make modern logistics become one of the fastest growing industries in the world. As an important part of the supply chain, the impact of logistics system on economic activities has become increasingly obvious, more and more attention has been paid to it, and it has become the "most important competitive field". In the future market competition, logistics will play an important role. As an all-round and multi-functional form of modern logistics, distribution center integrates logistics, business flow, information flow and many other activities. With its economic and effective service mode, it ensures the needs of socialized mass production. In developed countries, distribution center has been popular for decades and has been generally accepted by producers and operators; As an advanced way of circulation, it will have a positive impact on the marketization, socialization and modernization of China's circulation industry [1]. To develop and standardize modern marketing methods such as logistics distribution is the need of the development of market economy. Developing logistics distribution center is an important measure to liberate the productive forces of production, circulation and consumption.

In the mid-1980s, China began to study the logistics problem, and the word "distribution center" appeared. After entering the 1990s, the entity of "distribution center" appeared. After the system reform, drawing on the advanced experience of foreign countries, the Ministry of internal trade has carried out the pilot work of distribution centers in Shanghai and Guangzhou since 1992 to guide the state-owned enterprises to transform into socialized logistics distribution centers [2]. In 1996, the Ministry of Internal Trade issued the notice on strengthening the development and construction of commercial logistics distribution center, drafted the development plan of logistics distribution center, and put forward the development policy of "transforming mechanism, intensive operation, improving function, developing logistics and increasing strength". In 2001, the state formulated a preliminary plan for the development of logistics distribution in the next five years. The plan includes supporting and standardizing the development of $\sim$ a batch of third-party logistics enterprises, striving for more than $50 \%$ of the proportion of 
socialized distribution enterprises at the end of the Tenth Five Year Plan Period: building a number of logistics enterprises with reasonable scale in major commodity production, scattered areas and transportation roots in large and medium-sized cities To build a national logistics distribution network, we should establish a standardized modern commodity logistics center and a specialized distribution center. A number of logistics distribution demonstration projects will be determined. In the central cities of all major regions in China, enterprises that meet the basic conditions of commodity logistics distribution will be selected, and specialized backbone logistics distribution enterprises that meet the modern commodity logistics distribution and have a national business network will be established.

From a nationwide perspective, China is ushering in an upsurge in the development of logistics distribution center, and chain enterprises all over the country are highly motivated to build distribution centers. Beijing, Shanghai, Guangzhou and other places are planning the development of the city's distribution centers. Some of them are experimenting with key enterprises, while others are focusing on it as a major event of circulation reform. In addition, some large production enterprises are also focusing on the construction of distribution centers. Based on this, this paper studies the logistics informatization of industrial enterprises under the background of big data and its application in industrial supply chain management.

\section{Inventory control mode of logistics distribution center}

The difficulty of distribution center operation lies in information collection and processing, and in order management, which usually represents the inventory replenishment control mode of distribution center. According to the process of inventory distribution, inventory replenishment is divided into pull type and push type. The advantages of this inventory replenishment method are: each distribution center and node enterprise decide the order point and quantity by themselves, and the distribution center collects / delivers goods according to the order requirements.

The transaction cost of the distribution center is not high, because the distribution center only distributes goods according to the order, does not need to carry on the inventory transaction and the inventory balance between the distribution points, each distribution point and each node enterprise operates according to their own system, their contact with the distribution center is only the inventory supply connection, and the computer of the distribution center only processes the order.

The disadvantages of this inventory replenishment method are: only when the inventory drops to the order point, the distribution center will notice, which is not conducive to the overall deployment of the distribution center.

The operation of the system assumes that the inventory supply is stable and the lead time of order is fixed. Once the above conditions change, there will be out of stock. Each distribution point operates independently of the distribution center, so it is difficult to allocate inventory among distribution points.

This pull inventory replenishment uses the method of reorder point and economic lot size, that is, to decide when to order and then how much to order. Its characteristics are as follows:

(1) the distribution point makes inventory replenishment decision, and the distribution center responds quickly after receiving the order from the distribution point;

(2) In a certain period of time, the comprehensive demand may exceed the average planned demand. If several distribution points order at the same time, the total demand for ordering will rise during this period. When a large number of inventory arrives at the distribution center, it may exceed the capacity of the distribution center, and there will be problems of how to distribute the delivery order and delivery personnel, The last few distribution points that get delivery may be out of stock because they can't get delivery on time, which will delay business

ISSN: 0010-8189 
opportunities.

Push inventory replenishment means that the distribution center decides the delivery quantity and delivery time to the distribution point according to the relevant information. This inventory control method requires the use of distribution resource planning (DRP). The advantages of the inventory replenishment method are: (1) the distribution center can control the inventory to grasp the total demand of the whole supply chain as a whole, rather than only respond to a distribution point or a node enterprise.

(2) The distribution center delivers goods according to the scheduled plan, and can reach an agreement with the supplier first. Once the demand changes, the distribution center can negotiate with the supplier immediately to make adjustments;

(3) The distribution center can deliver goods when the distribution point needs, and when the node enterprise needs raw materials, the characteristic is that it can truly achieve the first in first out of inventory.

The disadvantages of this inventory method are:

(1) the effective operation of the distribution center depends on the good communication between the distribution center and the node enterprises and distribution points, especially some special information should be timely fed back to the distribution center.

(2) The power of distribution points and node enterprises is weakened. The distribution center distributes raw materials and purchased parts to the node enterprises according to the predicted plan, and delivers goods to the distribution points. The node enterprises and distribution points no longer control their actual inventory. The cost of information system configuration and maintenance is high. The distribution center needs to balance the inventory transportation and stock of all distribution points, and master the actual production situation of node enterprises. Therefore, the investment of information technology is large, and it also needs to be upgraded regularly or irregularly according to the actual situation.

This inventory replenishment method requires the use of distribution resource planning (DRP), which has the following characteristics:

(1) to forecast the inventory according to the actual situation of each node enterprise and distribution point, instead of simply summarizing the inventory data of each node enterprise and distribution point;

(2) It applies the MRP principle to automatically update the related data of dependent demand and inventory. Under the traditional supply chain logistics operation mode, the core enterprises have to spend a lot of energy to select and assess suppliers and distributors, so that sales and procurement can proceed smoothly; At the same time, some core enterprises have to implement the so-called JIT Procurement in order to reduce inventory as much as possible, reduce logistics costs and improve their core competitiveness, which forces suppliers to increase the number of deliveries to ensure that they can be delivered to the right place at the right time, thus bringing the problem of small batch of high-frequency deliveries to suppliers, leading to the increase of logistics costs of suppliers; Sometimes, in order to prevent delivery delay, suppliers are fined a lot, and they have to add warehouses or rent others' warehouses in the location of core enterprises, which will inevitably lead to the increase of logistics costs of suppliers. Although the logistics cost of core enterprises may be reduced, its reduction is based on the rising logistics cost of suppliers. The logistics cost of the whole supply line has not been reduced, and the competitiveness has not been enhanced.

On the other hand, in the traditional supply chain logistics operation mode, the information in the supply chain is transferred layer by layer. There is a certain deviation between the actual demand of the end users and the 
predicted demand. This deviation is transmitted to the upstream distributors and manufacturers through the retailers. Due to the existence of order lead time, the deviation between the actual demand and the order quantity becomes larger and larger with the transfer to the upstream, which may produce the "bullwhip effect", leading to the substantial deviation between the actual demand and the forecast quantity, thus greatly weakening the efficiency of the supply chain, and ultimately harming the interests of all members. The main reason for this "bullwhip effect" is the delay of information transmission, and the member enterprises of the supply chain can not share information. In view of this situation, each node enterprise in the supply chain is exploring a new alliance or cooperative logistics operation mode. Through this kind of cooperative logistics system, the original impossible logistics efficiency can be achieved, and the results created can be shared by all participating enterprises, so as to achieve the "win-win" effect. The practical experience of foreign countries shows that the establishment of logistics distribution center is the most effective way to reduce the logistics cost and improve the logistics operation efficiency of supply chain.

Figure 1 shows the operation mode of supply chain logistics based on distribution center. The core enterprises, the member enterprises in the supply chain and the third-party professional logistics companies join hands to build the logistics distribution center, which is responsible for all the logistics activities in the supply chain, including the centralized purchase of raw materials, the collection / delivery transportation, classified packaging and circulation processing of the node enterprises, etc. Due to the participation of supply chain members and the professional logistics ability of the third party logistics company, the distribution center can not be called the real fourth party logistics (4PL), but it has the essence of the fourth party logistics. In this way, we can reengineer or redesign the logistics supply chain to make the whole supply chain more reasonable, the logistics channel more smooth and the information transmission more fast.

\section{Logistics \& Supply Chain}

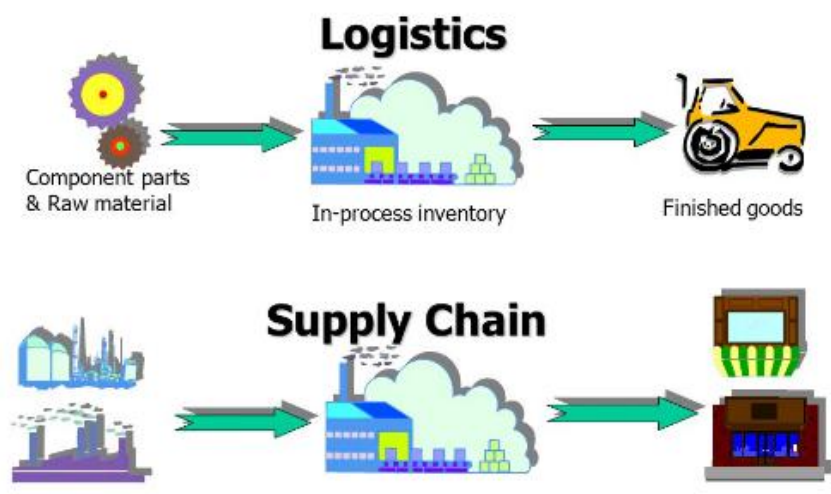

Figure 1. The operation mode of supply chain logistics based on distribution center

The logistics distribution center in Figure 2 is the information center and scheduling center of the whole supply chain. It implements push inventory replenishment control mode for downstream distributors and retailers. The distribution center controls and manages the inventory of distributors and retailers and delivers goods according to the predicted plan. Ensure that the distribution center can grasp the demand of the whole supply chain as a whole, not just respond to a distributor or retailer. The pull inventory replenishment control mode is implemented for upstream parts suppliers and raw material suppliers, and the distribution center collects or delivers goods according to the received order or delivery note. Each node enterprise of the supply chain focuses on its own core competence and can implement JIT Procurement. The distribution center optimizes the scheduling of vehicles according to the delivery / collection situation of each node enterprise in the supply chain, so as to ensure that the goods needed in the whole supply chain can arrive at the right place at the right time; At the same time, the logistics cost of the supply chain can be minimized to achieve a win-win situation for all members of the supply chain. 
Under the operation mode of supply chain logistics based on distribution center, the information transmission is network, and the distribution center is the information center. With the Internet as the technical support, the electronic order system (EOS) and electronic data interchange (EDI) technology are used to obtain the demand and supply information from the end users or node enterprises. On the one hand, the deviation between the actual demand and the predicted demand is reduced, And the amplification ratio of this deviation in the transmission process is controlled, which effectively solves the problem of "bullwhip effect". On the other hand, it improves the ability of the whole supply chain to quickly respond to customer demand, and realizes real-time sale, real-time manufacturing and real-time supply. That is to say, through the optimal combination of supply chain member enterprises, the demand information acquisition and subsequent response are as close to real-time as possible, and the lead time of customer demand is reduced to the minimum, so as to obtain the time and space advantages of market competition. All of this benefits from the sharing and fast transmission of information in the distribution center. The supply chain operation management mode based on the distribution center has become one of the development directions of the supply chain logistics management because it realizes the integrated management of the logistics in the supply chain, effectively reduces the logistics cost and improves the logistics operation efficiency of the whole supply chain. In the future, the distribution center will serve not only one supply chain, but also other supply chains, even enterprises in a certain area. It will integrate the resources of several supply chains and even a region to provide more and better quality services for more enterprises.

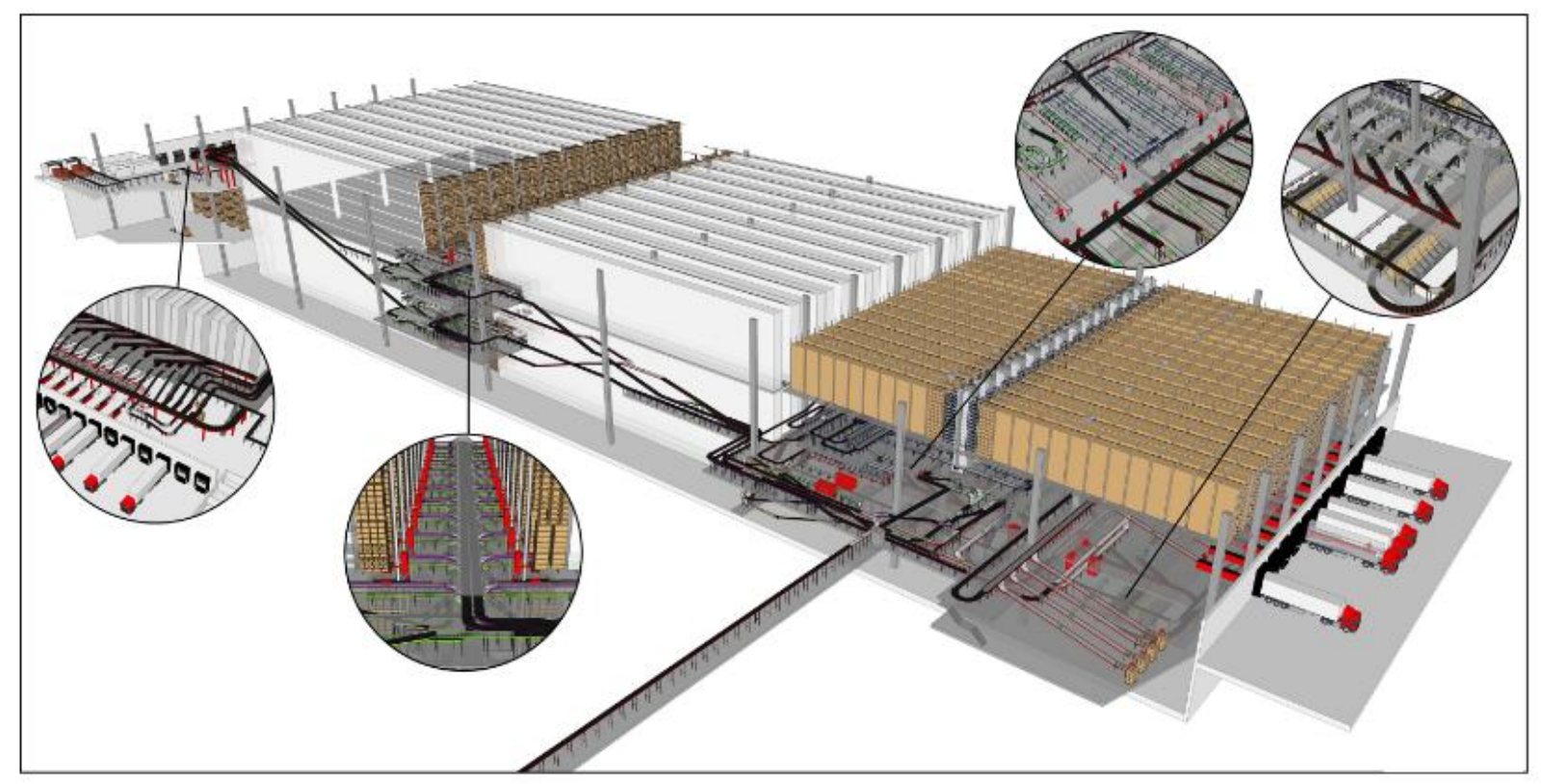

Figure 2. The logistics distribution center

\section{System Design}

According to the problems of imperfect storage environment, quality information and logistics status information channels of raw and fresh meat, the quality and safety information monitoring subsystem and logistics monitoring subsystem of raw and fresh meat were built respectively, and the two subsystems were integrated into the supermarket e-commerce system. The focus is to collect the quality and safety information and logistics tracking information of fresh meat products in real time, and integrate them into the e-commerce commodity interface. The purpose of this system is to solve the problem that consumers can't master the quality and safety information and logistics distribution status of raw meat products when they purchase online, and to provide the storage environment, quality, logistics status and other data information of the whole process from purchase to distribution at the front desk of e-commerce, so as to create a better shopping experience. 
System functional requirements are shown as following [3-5]:

(1) Real time monitoring of fresh meat safety information: the safety information of fresh meat includes its own quality information and storage environment information. According to the freshness index stipulated in the national standard, the quality information should be provided with a reasonable and reliable detection method and data analysis process. And in order to promote the real-time detection in supermarkets and other fresh stores, the equipment and methods need to meet the characteristics of portable, simple, fast and reliable. The storage environment information of raw and fresh meat is collected and displayed in real time according to the general environmental index requirements of raw and fresh meat storage.

(2) Cold chain logistics status tracking: the distribution of fresh goods must meet the requirements of fast and intact. Supermarket stores are widely distributed, directly from the store to the customer's hand, is also the basis of rapid distribution. However, consumers are suspicious of the logistics status, time and other information of fresh goods. Therefore, in the aspect of cold chain logistics status tracking, it is necessary to push the whole cold chain logistics status information in real time after consumers purchase fresh goods, and give the status information such as the logistics location and delivery time of goods at the e-commerce front desk.

(3) The integration of e-commerce system with fresh meat safety information and logistics status information subsystem "" after solving the problem of safety information data source of fresh goods and real-time logistics status monitoring, how to make these two parts connect with e-commerce system and how to give full play to its potential value in online marketing are naturally considered. In the fresh commodity interface of e-commerce, the display function of the quality and safety information of the commodity is also an important part of the practical significance of this study. According to the functional requirements analysis, the system will realize the collection of fresh meat freshness, storage environment, logistics status and other information, which will be displayed in the e-commerce system after analysis and processing. The whole function implementation process needs to go through a series of links, such as sensor data collection, network transmission, database storage, data analysis and processing, web foreground display and so on. The functional structure of the system is shown in Figure 3.

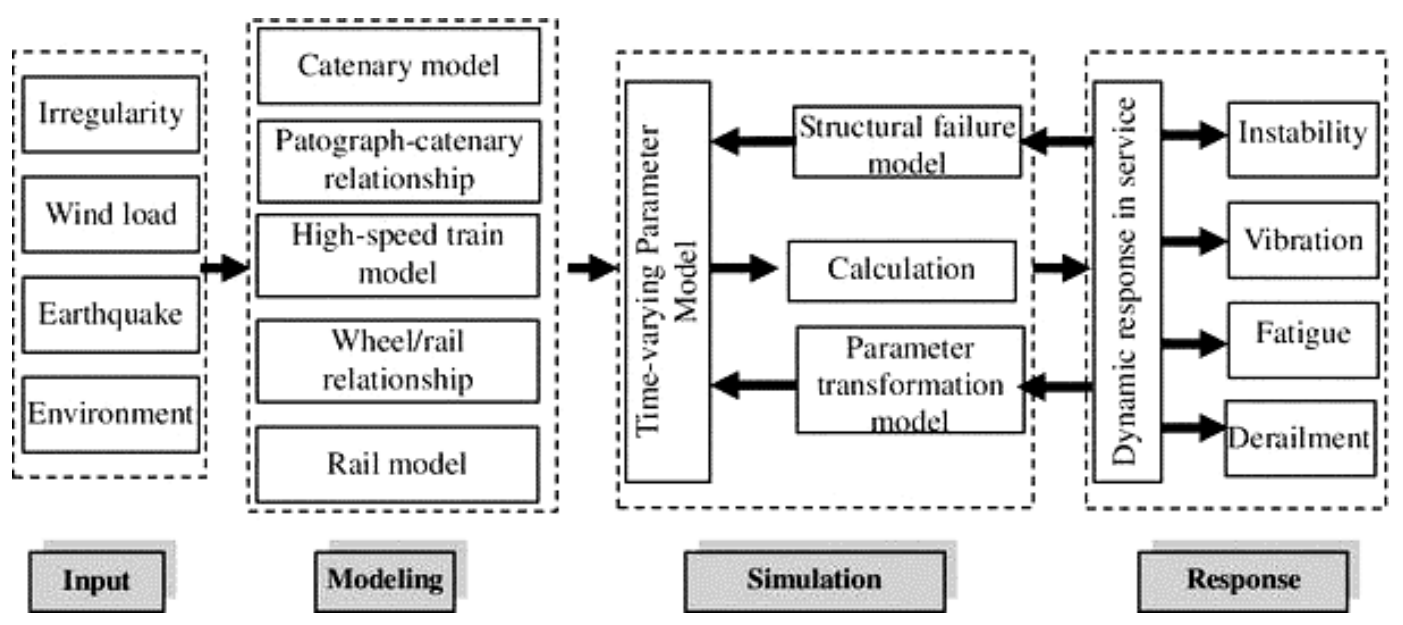

Figure 3 The functional structure of the system

The whole structure of the system needs to design the e-commerce platform, database, the underlying sensor network and the interface of each part. In order to meet the functional requirements of the system, and ensure the stable performance of the system, as well as the subsequent upgrade and expansion, the three-tier structure of the Internet of things is adopted when building the system [6]. The communication and data transmission of the system are mainly through the Internet, and the extra bandwidth is provided according to the demand to meet the larger data flow. The system architecture will be divided into application layer, network layer and perception layer. The 
relative independence and coordination between layers can effectively achieve security, portability and scalability. Logically, the system can be divided into database server (Data Management), application server (data processing), J2EE application layer (system middleware, etc.) and web presentation layer (Web Service) [7]. Vertically, each layer can be deployed in different physical machines, horizontally, it can be expanded by using server cluster technology, with good scalability and performance indicators. The specific software and hardware construction of the system will be described in detail below.

According to the requirement analysis, the whole system will be divided into relatively independent subsystems, and finally these functional modules will be integrated according to their level in the system. These subsystems include e-commerce web platform, fresh quality and safety information real-time monitoring system, logistics monitoring system, RFID encoding / parsing system, real-time video system, etc. [8]. The front-end program of ecommerce platform belongs to the application layer, and its background and data interaction will be completed in the network layer. The real-time monitoring system of fresh quality and safety information, logistics monitoring system, RFID coding / analysis system, the lower computer of these subsystems belong to the perception layer, and the upper computer and its matching database service will be carried out in the network layer. The design of ecommerce front desk is based on B / S architecture with high portability and compatibility. The application of advanced HTML5 standard for page coding greatly improves the reliability of the system. Oracle database is used to improve the query efficiency and reduce the storage redundancy. The data interaction process between ecommerce platform and product database is completed by middleware written in Java [9].

Fresh quality and safety information real-time monitoring system, logistics monitoring system is designed using wireless sensor technology. The transmission of its monitoring network adopts ZigBee transmission. ZigBee nodes with various sensors are designed. After the ZigBee nodes are bootstrap networking, the ZigBee sensor nodes upload the collected data [10]. The system structure of ZigBee is shown in Figure 4. All the data will be gathered in the gateway node (Coordinator), and the network nodes will be uploaded to the server for computing stored procedures.

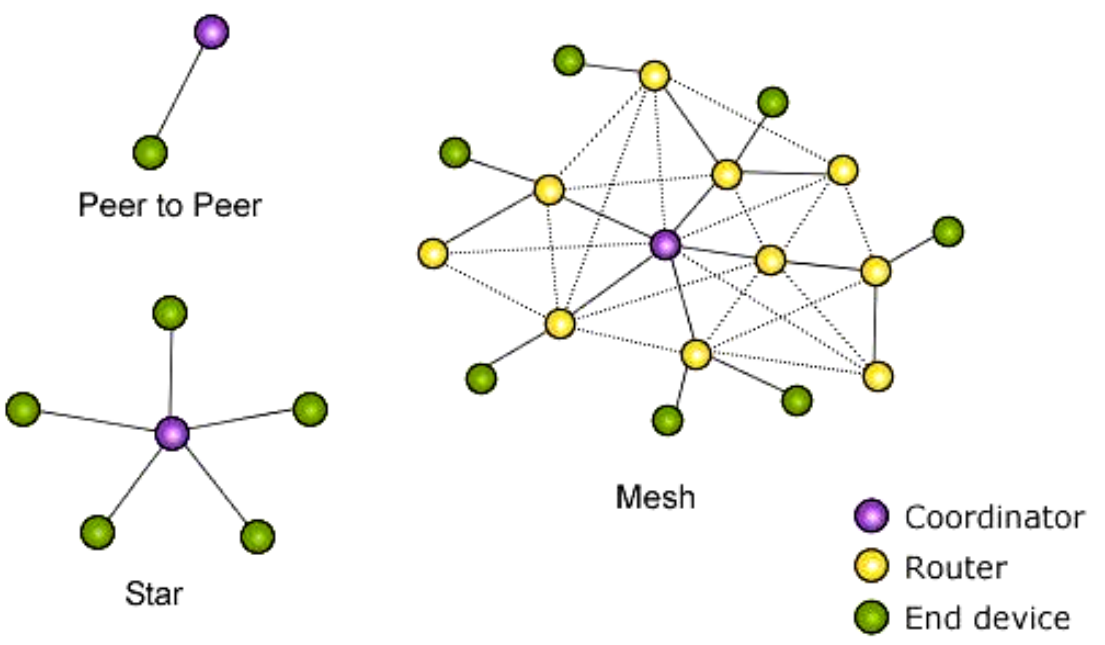

Figure 4The system structure of ZigBee

As shown in Figure 5, the relevant data sources of fresh meat products can be roughly divided into three aspects according to the type of Technology: RFID encoding / parsing system, wireless sensor network, and real-time network video system. RFID coding / parsing system is mainly to bundle each batch of products to determine the unique identity of each product; The main function of wireless sensor network in production, processing and logistics is to monitor process data; Real time network video system is mainly responsible for providing real-time video service. After the information is processed by the servers of these three systems, it can be pushed to the fresh commodity interface foreground, agricultural products supervision platform, cloud computing platform and other 
applications. The whole information system can be divided into four subsystems according to function realization, including fresh meat quality and safety information monitoring system, logistics monitoring system, video realtime monitoring system, RFID coding / analysis system. In terms of the application on the e-commerce platform of agricultural products, the software and hardware architecture of this system has opened up the whole production and marketing process under the $\mathrm{O} 2 \mathrm{O}$ mode or entity sales mode of agricultural products, and enriched many functions of the whole industrial chain, such as monitoring, tracing, scheduling optimization, quality assurance, etc..

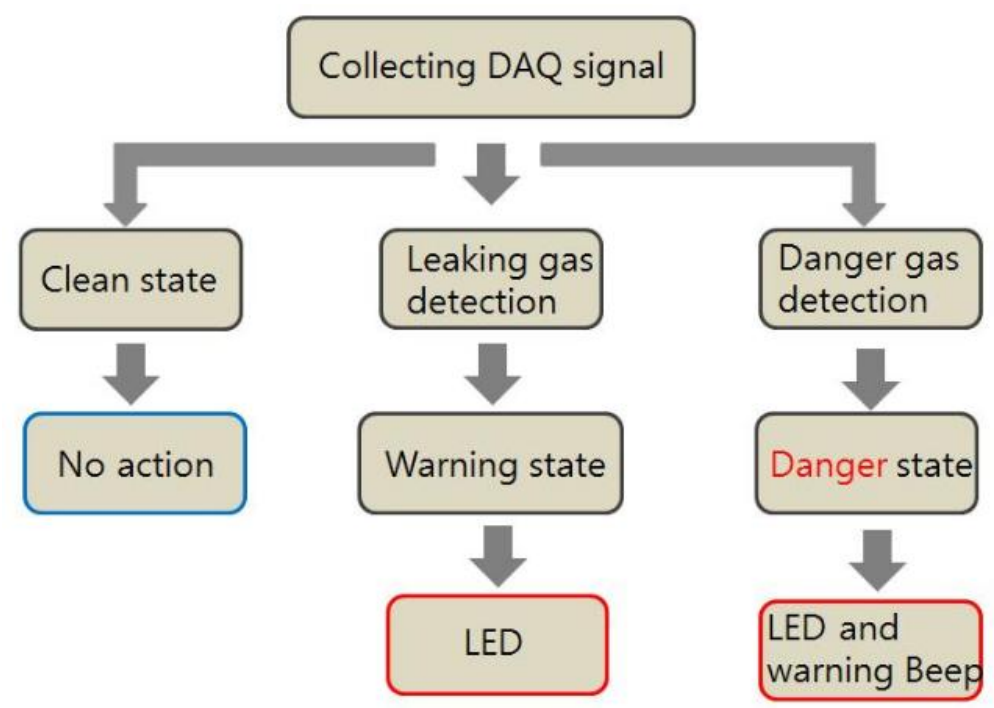

Figure 5 Overall system architecture

\section{Conclusion}

This paper mainly studies the operation mode of logistics distribution center, including the basic function, operation process, inventory control technology and inventory replenishment mode of logistics distribution center. Finally, it introduces the operation mode of supply chain logistics based on distribution center. It lays a foundation for the research on the infrastructure of logistics center information system.

\section{References}

[1] Hu Yuefei, Huang Shaoqing. Supply Chain Finance: Background, Innovation and Concept Definition. Financial Research, 2009

[2] Zhao Yajuan, Yang Xisun, Liu Xinbao. Supply Chain Finance and the Improvement of SMES' Credit Capacity. Financial Theory and Practice, 2009, 000 (010): 46-51

[3] Yang Yanzhong. On Risk Prevention of Supply Chain Finance of Commercial Banks. Financial Forum, 2007 (10): 44-47

[4] Yan Junhong, Xu Xiangqin. Analysis of Sme Financing Mode Based on Supply Chain Finance. Shanghai Finance, 2007, 2: 14-16

[5] Guo Ju'e, Shi Jinzhao, Wang Zhixin. Research on the Evolution and Risk Management of Online Supply Chain Financial Model Based on the Third Party B2b Platform. Business Economics and Management, 2014, 1: 13-22

[6] Song Hua, Yang Xuan. Research on the Impact of Smes' Competitiveness and Network Embeddedness on Supply Chain Financial Performance. Journal of Management, 2018, 15 (004): 616-624

[7] Li Shushan, Li Shushan. Supply Chain Finance Model of Order to Factoring Financing Mode. Acta Physica Sinica, 1984, 33 (11): 1501-1511 
[8] Shen Aizhong, Guo Jinli, Soqi. Modeling and Analysis of Supply Chain Finance Based on Multi-layer Network. Computer Application Research, 2017, 034 (012): 3628-3631

[9] Yan Nina, Sun Baowen. Optimal Strategy of Supply Chain Finance Under Warehouse Receipt Pledge Financing Mode Considering Credit Limit. System Engineering Theory and Practice, 2011 (09): 60-65

[10] Xie Shiqing, He Bin. Analysis of Three Typical Models of International Supply Chain Finance. Economic Theory and Economic Management, 2013, V33 (004): 80-86 